Obere Extremität 2020 $\cdot 15: 310-315$ https://doi.org/10.1007/s11678-020-00595-9 Received: 15 April 2020

Accepted: 6 August 2020

Published online: 9 September 2020

(c) The Author(s) 2020

\author{
Kilian Wegmann $n^{1,2} \cdot$ Nadine Ott $^{1,2} \cdot$ Tim F. Leschinger ${ }^{1,2} \cdot$ Andreas Harbrecht $^{1,2} \cdot$ \\ Lars P. Müller ${ }^{1,2} \cdot$ Michael Hackl $^{1,2}$ \\ ${ }^{1}$ Center for Orthopedic and Trauma Surgery, University Medical Center, Cologne, Germany \\ ${ }^{2}$ Cologne Center for Musculoskeletal Biomechanics, Medical Faculty, University of Cologne, Cologne, \\ Germany
}

\title{
Prosthetic replacement of the radial head
}

\section{Proximal osteolysis and correlation with patient characteristics and indication for index surgery}

are not fully understood; inflammatory, septic and mechanical factors are discussed. A less well-known form of bone loss around radial head implants has been observed in the clinical setting and is referred to as collar resorption. This describes bone loss at the proximal part of the radius, just distal to the neck of the prosthesis, which may arise during follow-up and is usually asymptomatic (• Fig. 1). Popovic et al. published their series on mid-term follow-ups of bipolar cemented radial head prostheses and reported a frequency of $31 \%$ of resorption just distal to the collar [20]. This entity is observed in various types of radial head prostheses. The present study aims to display the incidence of collar resorption in a monopolar press-fit implant and investigate whether it correlates with specific patient characteristics such as gender, age, indication for index surgery and the size of the implant used.

\section{Methods}

This is a monocentric retrospective cohort study on patients having undergone prosthetic replacement of the radial head. Therefore, after obtaining approval from the local ethics committee, the operative database of the authors' institution was reviewed. Patients that had undergone radial head prosthetic replacement during the years 2013 and 2018 and for whom a minimum radiological follow- up of 6 months was available were included. Patients that received a radial head prosthesis for unreconstructable fractures or that suffered from arthritic degeneration of the radial head articular surface were included. Primary arthritis cases, as well as secondary arthritis as in fracture sequelae, were included. All patients were treated with a monopolar press-fit implant (MoPyC, Tornier, France). Age, sex, indication for prosthesis and size of prosthesis were recorded. A total of 30 patients were included in the analysis; 15 patients were female and 15 were male. The mean age was 60.1 years (range $26-82 ; \pm$ SD 14.2). In 16 patients (10 male, six female), the indication was for trauma sequelae or revision; mean age was 56.5 years (range $32-82 ; \pm$ SD 12.15). In 14 patients (five male, nine female) the indication for radial head replacement was acute unreconstructable fracture of the radial head; mean age was 64.29 years (range 26-81; \pm SD 15.6). The implanted shaft size was "small" in seven patients, "medium" in 18 patients, "large" in four patients and "X-large" in one patient. The mean duration of X-ray follow-up was 23 months (range 6-72; \pm SD 16.1).

The clinical documentation of the patients was searched for symptoms of loosening as well as for data on revision surgery. Clinical outcome scores were not evaluated in this study. 

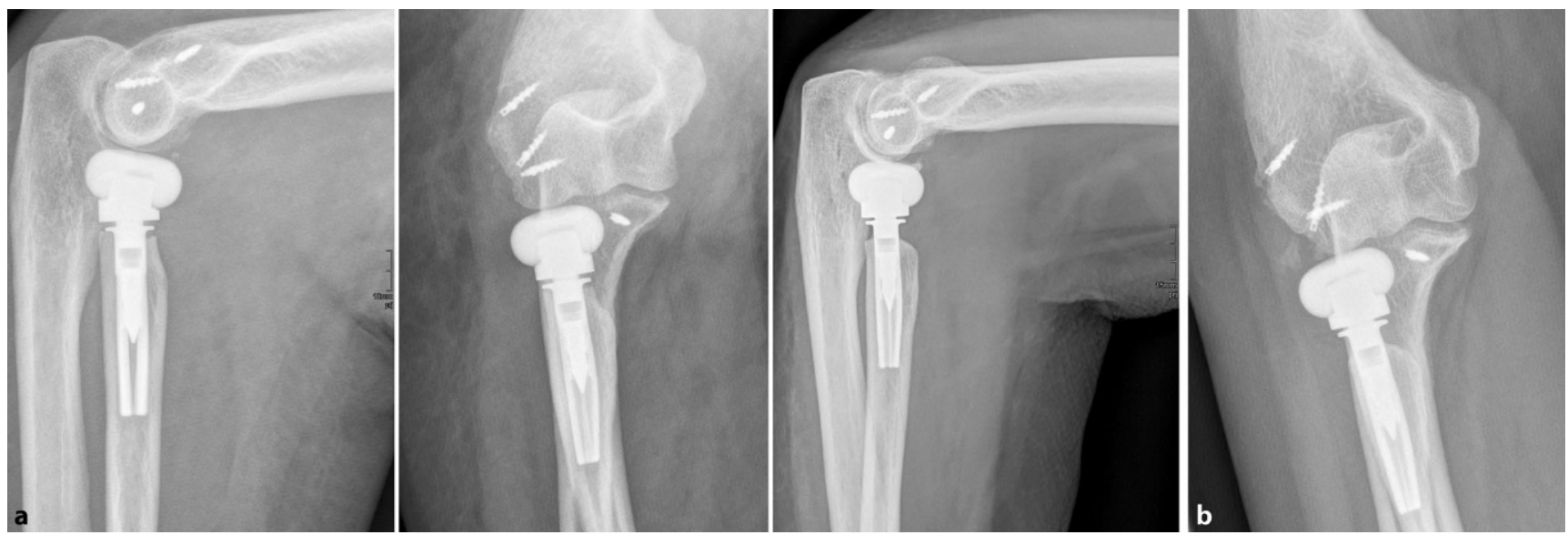

Fig. $1 \Delta$ a X-ray taken after index surgery for an unreconstructable Mason III fracture. b Osteolysis around the neck at 18 months follow-up. There has evidently been bone loss around the neck of the implant, whilst no signs of loosening of the shaft are present

\section{Surgical procedure}

Patients were operated in supine position, with the arm placed on an arm table. The Kocher approach was used in all procedures. The height of the prostheses was levelled at the posterolateral edge of the coronoid, according to current recommendations [13, 21-23]. Implantation was performed according to the manufacturer's recommendations. The collar of the implant was always abutting onto the proximal end of the shaft, at the level of the osteotomy. Hence, any gap between the collar and proximal end of the radial shaft found on the follow-up X-rays could be attributed to osteolysis of bone; if not, loosening and proximal migration of the implant was present. For closure titanium bone anchors were used to fix the lateral collateral ligament and the common extensor origin, before subtle suture of the fascia and skin closure.

\section{Analysis of imaging}

The anteroposterior and lateral X-rays available from the day after surgery, as well as 6 months after surgery, were evaluated. The authors focused on signs of loosening of the stem in the bony socket. Therefore, three areas of interest were selected according to three segments of the proximal radius, surrounding the shaft of the prosthesis. Segment 1 was set as the proximal third of the overall length of the prosthetic stem. Segment two was set to be the middle third, and segment 3 the distal third of the overall length of the radial shaft (• Fig. 2).

The three segments were investigated for signs of lucency between the bone and the implant, as well as for signs of resorption of bone mass. Migration of the shaft, or complete loosening of the prosthesis was documented. The extent of bony resorption along the shaft was also investigated. To measure the amount of bone loss (BL), in the lateral image, the length of the affected segment of the shaft component (LA) was set in relation to the overall length of the shaft (OL), according to the formula: $\mathrm{BL}=(\mathrm{LA} / \mathrm{OL}) \times 100$ (- Fig. 3). This yielded a percentage of bone loss of the overall bone. Measurements were performed at one time by the first author.

\section{Statistical analysis}

Descriptive statistics were taken from the measurements of the radiological imaging. Mean, minimum and maximum values as well as standard deviation were computed. Statistical differences were tested for significance using the MannWhitney $\mathrm{U}$ test, and the level of significance was set to $p<0.05$. Using the Pearson test for correlation, the results were correlated with the recorded characteristics of the cohort, such as age, sex, indication and prosthesis size and time of $\mathrm{X}$-ray.

\section{Results}

An analysis of the clinical patient records confirmed loosening and a corresponding revision procedure in only one patient. The others did not show clinical signs of loosening according to the records.

\section{Imaging analysis}

Of the 30 press-fit prostheses investigated, 28 showed proximal osteolysis in section 1 around the neck of the shaft, accounting for $93.3 \%$. The mean amount of osteolysis was $8.8 \% \pm$ SD. 6.0 (range, $0.00-26.1$ ) of the overall length of the prosthetic shaft. Of the 30 prostheses, one showed typical signs of shaft loosening with extensive radiolucent lines in the three contiguous zones, accounting for $3.3 \%$ of all cases and for $3.6 \%$ of the cases with proximal osteolysis. The loosening was found in a 70-year-old female patient. Revision surgery with resection of the implant showed a negative microbiology report, making aseptic loosening likely. With $18.5 \%$ of proximal osteolysis, the case with implant loosening showed the overall second highest amount of osteolysis around the neck. There was no significant difference $(p=0.64)$ in the amount of resorption in section 1 between the primary fracture cases (mean $8.8 \pm$ SD 4.5 ; range, $1.2-15.8$ ) and the group of secondary implantations due to 
Obere Extremität 2020 • 15:310-315 https://doi.org/10.1007/s11678-020-00595-9

(c) The Author(s) 2020

K. Wegmann · N. Ott · T. F. Leschinger · A. Harbrecht · L. P. Müller · M. Hackl Prosthetic replacement of the radial head. Proximal osteolysis and correlation with patient
characteristics and indication for index surgery

\section{Abstract}

Background. Radial head replacement is an established option in patients with comminuted radial head fractures and complex elbow trauma. While studies demonstrated that asymptomatic radiolucencies around the stem are common, the incidence and clinical significance of bone loss at the proximal part of the radius, just distal to the neck of the prosthesis (collar resorption), is unknown. Objectives. The aim of this retrospective study was to analyse the incidence of collar resorption after radial head replacement and investigate whether this correlates with specific patient characteristics such as gender, age, indication for index surgery and the size of implant used.

Materials and methods. The study group consisted of 30 patients (average age 60.1 years) having undergone prosthetic replacement with a monopolar press-fit implant of the radial head at an average follow-up of 23 months. Indications for surgery included trauma sequelae or revision in 16 patients and acute, unreconstructable fractures of the radial head in 14 cases. Symptoms of loosening and revision surgery were recorded. Radiographs were analysed for signs of lucency between the bone and the implant as well as for signs of resorption of bone mass around the neck (section 1). These values were correlated with age, gender, indication for index surgery and size of implant.

Results. In all, 28/30 (93.3\%) prostheses showed proximal osteolysis around the neck of the shaft. Of the 30 , one prosthesis presented signs of shaft loosening. The average amount of osteolysis was $8.78 \%$ (range $0-26.1 \%$; $\pm 6.0 \%$ ) of the overall length of the prosthetic shaft (OL). There was no significant difference $(p=0.49)$ between the amount of resorption in section 1 between the primary fracture cases (8.75 $\pm 4.5 \%$; range $1.2-15.8 \%$ ) and the group of secondary implantations due to degeneration or fracture sequelae $(8.8 \pm 7.2 \%$; range $0-26.1 \%)$. Furthermore, the analysis did not reveal any statistically relevant correlations between the amount of neck resorption and the other cohort characteristics (age, gender, size of the components).

Conclusions. In the study cohort, a high amount of osteolysis/bone resorption was assessed around the neck of the press-fit radial head prosthesis used. However, no significant correlation between collar resorption, patient demographics and indication for index surgery was found at short-term follow-up.

Keywords

Radial head replacement · Revision . Osteolysis · Collar resorption - Prosthesis . Loosening

\section{Implantation von Radiuskopfprothesen. Proximale Osteolyse und ihre Korrelation mit Patientenmerkmalen sowie der Indikation zur Indexoperation}

\section{Zusammenfassung}

Hintergrund. Die Verwendung einer Radiuskopfprothese ist eine etablierte Option bei Patienten mit Trümmerfrakturen des Radiuskopfs und komplexen Ellbogentraumata. Eine Knochenresorption unterhalb der Kopf(-Hals)Prothesenkomponente am Übergang zum Schaft zeigt sich nicht selten als radiologische Auffälligkeit in den postoperativen Kontrollen. Die Inzidenz und klinische Signifikanz dieser Knochenresorption ist unbekannt.

Ziel der Arbeit. Ziel der Studie war es, die Inzidenz der Knochenresorption nach Implantation einer Radiuskopfprothese zu ermitteln und zu untersuchen, ob eine Korrelation mit bestimmten Patientenmerkmalen wie Geschlecht, Alter, Indikation zur Indexoperation und Prothesengröße bestand. Material und Methoden. Es wurden $30 \mathrm{~Pa}$ tienten (Durchschnittsalter 60,1 Jahre) nach Implantation einer MoPyC-Radiuskopfprothese und einem durchschnittlichen Follow-up von 23 Monaten eingeschlossen. Indikationen zur Operation waren Traumafolgen oder Revision bei 16 Patienten und akute nicht rekonstruierbare Frakturen des Radiuskopfs in 14 Fällen. Symptome der Prothesenlockerung und Revisionsoperationen wurden erfasst. Die Röntgenbilder wurden auf Zeichen von Strahlentransparenz zwischen Knochen und Prothese sowie auf Zeichen der Knochenresorption im Bereich des Halses (Sektion 1) untersucht. Diese Befunde wurde bezüglich einer Korrelation mit Alter, Geschlecht, Indikation zur Indexoperation und Prothesengröße überprüft.

Ergebnisse. Insgesamt 28 von 30 (93,3\%) Prothesen zeigten am Hals-Schaft-Übergang eine periprothetische Knochenresorption mit einer durchschnittlichen Länge von $8.78 \pm 6,0 \%$ (Range 0-26,1\%) in Relation zur Gesamtlänge des Prothesenschafts. Es bestand kein signifikanter Unterschied $(p=0,49)$ bezüglich des Ausmaßes der Resorption in Sektion 1 zwischen den Fällen mit Primärfraktur (8,75 $\pm 4,5 \%$; Range 1,2-15,8\%) und der Gruppe mit sekundärer Implantation wegen Degeneration oder Frakturfolgen (8,8 7,2\%; Range 0-26,1\%). Des Weiteren ergaben sich keine signifikanten Korrelationen zwischen dem Ausmaß der Resorption und den anderen Merkmalen des Studienkollektivs (Alter, Geschlecht und Prothesengröße).

Schlussfolgerungen. Im Studienkollektiv konnte ein häufiges Auftreten einer Osteolyse/Knochenresorption am Kopf/Hals-SchaftÜbergang der Prothese beobachtet werden. Diese Knochenresorption zeigte jedoch im Kurzzeit-Follow-up keine signifikante Korrelation mit den Patientenmerkmalen und der Indikation zur Revision.

\section{Schlüsselwörter}

Radiuskopfprothese - Revision - Osteolyse $\cdot$ Knochenresorption distal des Prothesenhalses · Prothese · Lockerung 


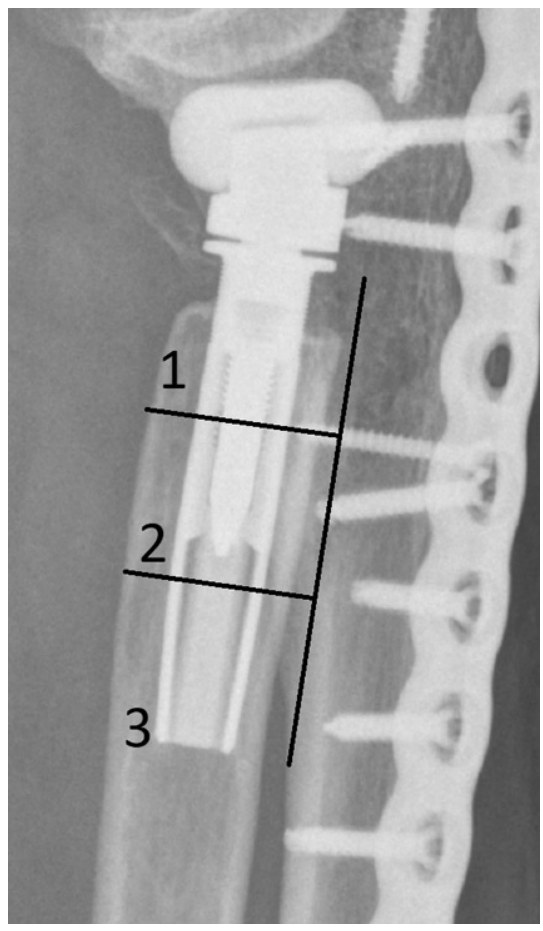

Fig. $2 \Delta$ The segmentation of the overall length of the implant in three sections is shown, with section 1 being the proximal, section 2 the middle and section 3 the distal segment

degeneration or fracture sequelae (mean $8.8 \pm$ SD 7.2; range, $0.0-26.1$ ).

\section{Correlation analysis}

The analysis did not find any statistically relevant correlations between the amount of neck resorption and the cohort characteristics. It showed only a weak correlation with patient age with $\mathrm{r}=-0.29$ and with the time of $\mathrm{X}$-ray follow-up $\mathrm{r}=0.24$. Also, gender and size of implant did not show statistical context. Finally, the indication did not correlate with the amount of neck resorption.

\section{Discussion}

The present study found a high amount of osteolysis around the neck of the pressfit prosthesis used. In conclusion from the analysis of the imaging and clinical records, proximal osteolysis is common in the investigated implant and is not indicative of loosening within the investigated follow-up period. It does not cor-

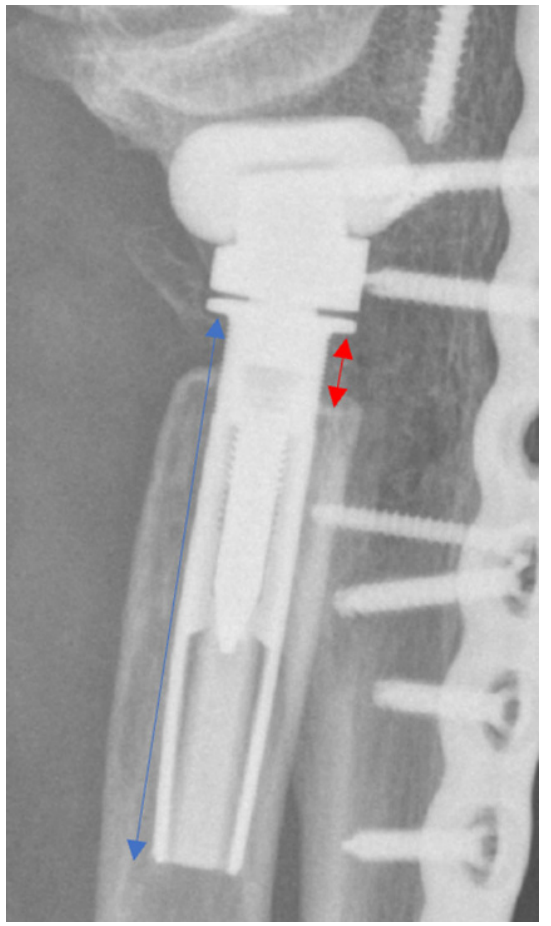

Fig. $3 \Delta$ Digital measurements for bone loss: the red arrow represents the length of the affected segment of the shaft component (LA), while the blue arrow measures the overall length of the shaft $(\mathrm{OL})$, which are set in relation according to: $B L=(L A / O L) \times 100$

relate with patient demographics in the present cohort.

Pathologies of the radial head, like fractures or degeneration, represent clinically relevant entities. In the case of radial head fractures, which are common lesions accounting for up to $20 \%$ of all elbow injuries, anatomical reconstruction and repair of the commonly accompanying lesions should always be the primary goal if significant displacement is present [24]. Only unreconstructable fractures should be replaced by a prosthetic implant, as the authors do not believe that the high energy injuries that often accompany traumatic joint instability can be treated with head resection alone. Several studies have shown the biomechanical benefits of replacing an absent radial head with an implant, both for valgus stability and for function of the interosseous membrane $[5,6,25]$. However, as clinical studies found, prosthetic replacement of the radial head comes with complications, with loosening being the most common one together with overstuffing [26]. The most commonly observed loosening is aseptic loosening [9].

The study by Popovic et al. investigated in detail the radiological and functional outcome of cemented bipolar radial head prostheses [20]. The authors included 51 patients that had received a radial head replacement for unreconstructable fractures. An intensive analysis was performed regarding signs of osteolysis and bone loss around the stem of the implant. The results showed that in 16 patients, accounting for $31 \%$, bone loss around the neck of the prosthesis was found. Besides that, $53 \%$ of the patients showed peri-prosthetic lucencies, and in $10 \%$ progressive loosening was present. The authors concluded that the proximal bone loss might be caused by wear debris and a subsequent inflammatory response, or due to altered loading at the neck, as a result of the modified mechanical properties that arise with the implant. Aseptic loosening is most likely a product of mechanical failure of the implant, where the fixation of the implant is overcome by its load [27]. But also, as shown for other joints, inflammatory factors may play a role as a response to particle wear [27]. Loosening can also be as a result of infection, where inflammatory agents and bacteria lead to bone resorption and, consecutively, loss of fixation of an implant [28]. However, the aforementioned patterns of loosening at the elbow usually happen along the shaft of the prosthesis. Osteolysis below the neck of a radial head implant has only been investigated in a handful of studies. Laumonerie et al. found osteolysis around the neck of the implant in $33 \%$ of patients after implantation of the MopYc prosthesis [29]. The authors performed a meta-analysis, reporting on a total of 171 patients, and explained the high rate of proximal loosening with the auto-expanding mechanism of the pressfit implant, leading to stress shielding. Based on the authors' findings, they also do not believe that the described bone loss is a sign of loosening. They believe that the observed osteolysis is occurring according to Wolff's law (Julius Wolff 1836-1902), as a result of decreased mechanical loading in that area [30]. As frequently observed with hip replacement, 
prosthetic implants reduce the mechanical stress on certain areas of bone as the load is transferred via the prosthesis [31]. This phenomenon is known as "stress shielding". Wolff's law says that alteration of mechanical stress will lead to bone remodelling. In the case of reduced load, bone resorption takes place. This might be the case in the investigated press-fit implant. As it finds stable anchorage at the mid-section of the shaft component, the area under the neck sees a reduction in load, thus resulting in bone resorption. The data presented here can neither confirm nor exclude whether the proximal osteolysis leads to loosening of the implant. In total hip arthroplasties it could be shown that a high amount of stress shielding contributes to or even causes loosening [30]. Although on the basis of the current data it is tempting to see no association between proximal osteolysis and loosening in general, due to only one case of loosening in the cohort, the limitations of the study do not allow a final assessment. On the one hand, with 30 patients, a limited cohort size is presented. Implantation numbers for radial head prostheses are small compared to other implants like in the knee or the hip. Therefore, it is always challenging to achieve large cohorts for elbow prosthetic implants. It would be of benefit to have a larger cohort to investigate in this regard. Multicentric studies would likely be beneficial to this end. Due to the number of cases, it was not possible to create subgroups according to accompanying lesions or pathologies, which might obscure the results of the present study. Another limitation is the lack of clinical outcome data, which would enable correlations to be drawn between the amount of resorption and functional scores. This would make it easier to judge the effect of that bone resorption on the patient's well-being. Also, only one implant was investigated; therefore, it remains to be investigated whether other press-fit prostheses show similar areas of resorption.

\section{Practical conclusions}

To summarize the present study, the authors conclude that the finding of neck resorption in a press-fit radial head pros- thesis shows no correlation with the cohort characteristics. This may be due to mechanical factors or infection, which can lead to resorption of the bone stock around the shaft component of the prosthesis. Mechanical loosening probably occurs due to a combination of compression and bending and may be influenced by inflammatory processes caused by wear debris.

\section{Ethical requirements}

This monocentric retrospective cohort study was approved by the local ethics committee.

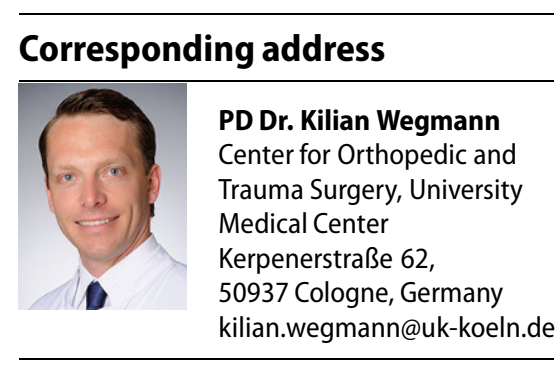

Funding. Open Access funding provided by Projekt DEAL.

\section{Compliance with ethical guidelines}

Conflict of interest. K. Wegmann has received travel expenses from Tornier. L.P. Müller receives consultancy fees from Tornier. All authors receive research support from Tornier. N. Ott, T.F. Leschinger, A. Harbrecht and M. Hackl declare that they have no competing interests.

For this article no studies with human participants or animals were performed by any of the authors. All studies performed were in accordance with the ethical standards indicated in each case..

Open Access. This article is licensed under a Creative Commons Attribution 4.0 International License, which permits use, sharing, adaptation, distribution and reproduction in any medium or format, as long as you give appropriate credit to the original author(s) and the source, provide a link to the Creative Commons licence, and indicate if changes were made. The images or other third party material in this article are included in the article's Creative Commons licence, unless indicated otherwise in a credit line to the material. If material is not included in the article's Creative Commons licence and your intended use is not permitted by statutory regulation or exceeds the permitted use, you will need to obtain permission directly from the copyright holder. To view a copy of this licence, visit http://creativecommons.org/licenses/by/4.0/.

\section{References}

1. Doornberg JN, Parisien R, van Duijn PJ, Ring D (2007) Radial head arthroplasty with a modular metal spacer to treat acute traumatic elbow instability. J Bone Joint Surg Am 89(5):1075-1080

2. Grewal R, MacDermid JC, Faber KJ, DrosdowechDS, King GJ (2006) Comminuted radial head fractures treated with a modular metallic radial head arthroplasty. Study of outcomes. J Bone Joint Surg Am 88(10):2192-2200

3. Marsh JP, Grewal R, Faber KJ, Drosdowech DS, Athwal GS, King GJ (2016) Radial head fractures treated with modular metallic radial head replacement: outcomes at a mean follow-up of eight years. JBone Joint Surg Am 98(7):527-535

4. Pugh DM, McKee MD (2002) The "terrible triad" of the elbow. Tech Hand Up Extrem Surg 6(1):21-29

5. Langohr GD, Willing R, Medley JB, King GJ, Johnson JA (2016) The effect of radial head hemiarthroplasty geometry on proximal radioulnar joint contact mechanics. J Hand Surg Am 41(7):745-752

6. Lanting BA, Ferreira LM, Johnson JA, King GJ, Athwal GS (2015) Radial head implant diameter: a biomechanical assessment of the forgotten dimension. Clin Biomech 30(5):444-447

7. Liew VS, Cooper IC, Ferreira LM, Johnson JA, King GJ (2003) The effect of metallic radial head arthroplasty on radiocapitellar joint contact area. Clin Biomech 18(2):115-118

8. Antoni M, Kempf JF, Clavert P (2020) Comparison of bipolar and monopolar radial head prostheses in elbow fracture-dislocation. Orthop Traumatol Surg Res. https://doi.org/10.1016/j.otsr.2019.10. 027

9. Viveen J, Kodde IF, Heijink A, Koenraadt KLM, van den Bekerom MPJ, Eygendaal D (2019) Why does radial head arthroplasty fail today? A systematic review of recent literature. EFORT Open Rev 4(12):659-667

10. Heijink A, Kodde IF, Mulder PG, Veltman ES, Kaas L, van den Bekerom MP et al (2016) Radial head arthroplasty: a systematic review. JBJSRev. https:// doi.org/10.2106/JBJS.RVW.15.00095

11. Vannabouathong C, Venugopal N, Athwal GS, Moro J, Bhandari M (2020) Radial head arthroplasty: fixed-stem implants are not all equal-a systematic review and meta-analysis. JSES Int $4(1): 30-38$

12. Viveen J, Kodde IF, Koenraadt KL, Beumer A, The B, Eygendaal D (2017) Clinical and radiographic outcome of revision surgery of radial head prostheses: midterm results in 16 patients. JShoulderElbow Surg 26(3):394-402

13. Athwal GS, Rouleau DM, MacDermid JC, King GJ (2011) Contralateral elbow radiographs can reliably diagnose radial head implant overlengthening. JBone Joint Surg Am 93(14):1339-1346

14. Hackl M, Wegmann K, Hollinger B, El-Zayat BF, SeyboldD, Guhring Tetal (2019) Surgical revision of radial head fractures: a multicenter retrospective analysis of 466 cases. J Shoulder Elbow Surg 28(8):1457-1467

15. Heijink A, Morrey BF, Eygendaal D (2014) Radiocapitellar prosthetic arthroplasty: a report of 6 cases and review of the literature. J Shoulder Elbow Surg 23(6):843-849

16. Van Riet RP, Van Glabbeek F, Verborgt O, Gielen J (2004) Capitellar erosion caused by a metal radial head prosthesis. A case report. J Bone Joint Surg Am 86(5):1061-1064

17. Burkhart KJ, Wegmann K, Schneider MM, Nietschke R, Hollinger B, Müller LP (2019) Klinische 
Relevanz des Overlengthenings in der Radiuskopfendoprothetik. Obere Extrem. https:// doi.org/10.1007/s11678-019-00546-z

18. HackI M, Burkhart KJ, Wegmann K, Hollinger B, Lichtenberg S, Muller LP (2015) From radial head to radiocapitellar to total elbow replacement: a case report. Int J Surg Case Rep 15:35-38

19. O'Driscoll SW, Herald JA (2012) Forearm pain associated with loose radial head prostheses. JShoulder Elbow Surg 21(1):92-97

20. Popovic N, Lemaire R, Georis P, Gillet P (2007) Midterm results with a bipolar radial head prosthesis: radiographic evidence of loosening at the bone-cement interface. J Bone Joint Surg Am 89(11):2469-2476

21. Van GlabbeekF, Van Riet RP, Baumfeld JA, Neale PG, O'Driscoll SW, Morrey BF et al (2004) Detrimental effects of overstuffing or understuffing with a radial head replacement in the medial collateralligament deficient elbow. J Bone Joint Surg Am 86(12):2629-2635

22. Van GlabbeekF, van Riet RP, Baumfeld JA, Neale PG, O'Driscoll SW, Morrey BF et al (2005) The kinematic importance of radial neck length in radial head replacement. Med Eng Phys 27(4):336-342

23. Wegmann K, Zhang W, Strauss V, Ries C, Muller LP, Burkhart KJ (2016) Is the distal radioulnar variance useful for identification of radial head prosthesis overlengthening? A cadaver study. Eur J Med Res 21:12

24. van Riet RP, Morrey BF, O'Driscoll SW, Van GlabbeekF (2005) Associated injuries complicating radial head fractures: a demographic study. Clin Orthop Relat Res 441:351-355

25. Lanting BA, Ferreira LM, Johnson JA, Athwal GS, King GJ (2013) The effect of excision of the radial head and metallic radial head replacement on the tension in the interosseous membrane. Bone Joint J 95-B(10):1383-1387

26. Bonnevialle N (2016) Radial head replacement in adults with recent fractures. Orthop Traumatol Surg Res 102(1 Suppl):69-79

27. Cheung EV, O'Driscoll SW (2007) Total elbow prosthesis loosening caused by ulnar component pistoning. J Bone Joint Surg Am 89(6):1269-1274

28. Zoccali C, Teori G, Salducca N (2009) The role of FDG-PET in distinguishing between septic and aseptic loosening in hip prosthesis: a review of literature. Int Orthop 33(1):1-5

29. Laumonerie P, Tibbo ME, Kerezoudis P, Gauci MO, Reina N, Bonnevialle N et al (2018) Short to midterm outcomes of one hundred and seventy one MoPyC radial head prostheses: meta-analysis. Int Orthop 42(10):2403-2411

30. Joshi MG, Advani SG, Miller F, Santare MH (2000) Analysis of a femoral hip prosthesis designed to reduce stress shielding. J Biomech 33(12):1655-1662

31. Dattani R (2007) Femoral osteolysis following total hip replacement. Postgrad Med J 83(979):312-316 